\title{
Ruptured Hepatic Epithelioid Angiomyolipoma: A Case Report and Literature Review
}

\author{
Shogo Tajimaa Akira Suzuki $^{\mathrm{b}}$ Kiyoshi Suzumurab \\ Departments of ${ }^{a}$ Pathology and ${ }^{b}$ Surgery, Shizuoka Saiseikai General Hospital, \\ Shizuoka, Japan
}

\section{Key Words}

Hepatic epithelioid angiomyolipoma $\cdot$ Rupture $\cdot$ Transcatheter arterial embolization $\cdot$ Surgical resection

\begin{abstract}
A 38-year-old male was admitted to our hospital due to upper abdominal pain. Computed tomography revealed a hepatic angiomyolipoma ( $\mathrm{AML} ; 10.5 \times 9.5 \times 7.0 \mathrm{~cm}$ in size), which had ruptured into the space between the liver and the diaphragm. Following transcatheter arterial embolization, surgical resection was performed. The tumor consisted of epithelioid cells $(50-60 \%)$, mature fat (40-50\%), and thickened-wall blood vessels. Considering the amount of epithelioid cells and their positivity for E-cadherin and $\beta$-catenin, the tumor was diagnosed as hepatic epithelioid AML. Cases of ruptured hepatic AML are rare. To the best of our knowledge, this is the sixth case reported in the English literature.

(c) 2014 S. Karger AG, Basel
\end{abstract}

\section{Introduction}

Hepatic angiomyolipoma (AML), a tumor of the liver, is much rarer compared with its renal counterpart. AMLs are composed of the three following components: smooth muscle cells, adipocytes, and blood vessels. Initial documentation of this disease was by Ishak [1] in 1976, and approximately three hundred cases have been reported in the English literature [2-7]. Epithelioid AML was first described in the kidney by Pea et al. [8] in 1991 as a peculiar variant of AML. The term epithelioid is applied when one of the three components, such as smooth muscle cells, become relatively rounded and rich in cytoplasm. Only a few cases of hepatic epithelioid AML have been reported [3, 9]. Epithelioid AML has been demonstrated to express E-cadherin [10] and $\beta$-catenin [11] as well as classical markers of melanocytic and 
Tajima et al.: Ruptured Hepatic Epithelioid Angiomyolipoma: A Case Report and Literature Review

myogenic differentiation such as HMB45 and $\alpha$ SMA. Many cases of ruptured renal AML have been documented in the past [12]; however, ruptured hepatic AML are considered to be extremely rare.

We present a rare case of ruptured hepatic epithelioid AML in a patient admitted for abdominal pain. In addition, we also review the English literature regarding ruptured hepatic AMLs.

\section{Case Report}

A 38-year-old male was admitted to the emergency room with upper abdominal pain. Laboratory findings revealed an abnormal liver function (aspartate aminotransferase, 222 IU/l; alanine aminotransferase, $158 \mathrm{IU} / \mathrm{l}$ ). Viral hepatitis serology was negative. Contrastenhanced computed tomography (CT) revealed a large tumor in the posterior segment of the right hepatic lobe (S6,7). The tumor, measuring $10.5 \times 9.5 \times 7.0 \mathrm{~cm}$ in size, had heterogeneous components, with low-density areas corresponding to fat. It had ruptured into the space between the liver and the diaphragm at the upper surface of the posterosuperior segment of the right hepatic lobe (S7), with extravasation of contrast medium into a hematoma (fig. 1a). Therefore, a rupture of hepatic AML was suspected. Transcatheter arterial embolization was performed because the patient did not have anemia or hypotension. However, he suddenly developed fever, and elevation of white blood cell count $\left(22.0 \times 10^{9} / \mathrm{l}\right)$ and C-reactive protein $(21.9 \mathrm{mg} / \mathrm{dl})$ was detected. The hematoma surrounding the liver was drained, and although this hematoma was suspected of infection, it tested negative for bacterial infection. Although infection was not confirmed, surgical resection was planned considering the possibility of infection. On preoperative contrast-enhanced CT, a thickened fibrous capsule had formed around the hematoma (fig. 1b). In the reconstructed image of the sagittal section, it was easy to detect the ruptured point of the tumor (fig. 1c). Right lobectomy was performed, and the postoperative course was uneventful, with no sign of a tuberous sclerosis complex (TSC) or renal tumor.

The surgically resected specimen contained a ruptured tumor, which appeared extensively hemorrhagic and with no macroscopically appreciable fat component (fig. 1d). Microscopic examination did not detect any infection. Triphasic elements, epithelioid tumor cells (50-60\%), mature fat (40-50\%), and thickened-wall blood vessels, were observed (fig. 2a). A high-power view of the epithelioid cells displayed rounded or polygonal shape with abundant cytoplasm (fig. 2b). Some of them had enlarged or bizarre nuclei (fig. 2c); however, no mitotic figure was found. Epithelioid cells expressed HMB45 and $\alpha$ SMA (fig. 3a, b), which are classical markers of melanocytic and myogenic differentiation. They also displayed weak membranous positivity for E-cadherin and $\beta$-catenin (fig. 3c, d), molecules playing a role in cell-to-cell adhesion. Even though epithelioid cells with enlarged or bizarre nuclei were intermingled, Ki-67 (MIB-1)-positive cells accounted for $<1 \%$. Therefore, the tumor was diagnosed as an epithelioid AML without apparent malignant features. The cause of the rupture could not be found despite careful macroscopic and microscopic examinations. No ruptured vessel and aneurysm were revealed inside the tumor. Thrombi had formed in several arteries due to preoperative transcatheter arterial embolization. 
Tajima et al.: Ruptured Hepatic Epithelioid Angiomyolipoma: A Case Report and Literature Review

\section{Discussion}

AML of the liver is a much rarer neoplasm than that of the kidney. Given that $40-50 \%$ of patients with renal AML have TSC, association of hepatic AML with TSC is less frequent (6$25 \%$ of cases) [13].

AMLs show a characteristic expression of both melanocytic and myogenic markers. Sometimes, the cells with such expression become epithelioid in morphology. One of the definitions of epithelioid AML in the kidney is that epithelioid cells occupy $>10 \%$ of the tumor [14]; their membranous positivity for E-cadherin [10] and $\beta$-catenin [11] has been documented. In the present case, the epithelioid cell component occupied $50-60 \%$ of the tumor, and E-cadherin and $\beta$-catenin were weakly positive in a membranous pattern. Therefore, applying the renal standard, this case could be appreciated as epithelioid AML of the liver.

Histological factors predicting the malignant progression of renal epithelioid AML, such as cellular atypia $\geq 70 \%$ of epithelioid cells, $>2$ mitotic figures per $10 \mathrm{HPFs}$, atypical mitoses, and necrosis that were proposed by Brimo et al. [15], were not found in this case. Critical differences between renal and hepatic AMLs are not known; therefore, the hepatic epithelioid AML observed in the present case was treated as benign. However, careful follow-up is required because of the lack of reliable data regarding the malignant progression of hepatic epithelioid AMLs.

To the best of our knowledge, only five cases of ruptured hepatic AMLs have been reported in the English literature [3, 9, 16-18] (table 1). Tumor size ( $\geq 4 \mathrm{~cm}$ ) and intratumoral aneurysm $(\geq 5 \mathrm{~mm})$ are important factors predicting the rupture of renal AMLs [19]. The latter is probably influenced by the former because tumor growth increases internal blood flow, which leads to blood vessel dilatation and aneurysm formation. The blood vessels of AMLs may be vulnerable in nature because of their architectural abnormality. Using statistical analysis, the crucial cause of the rupture has been suggested to be the formation of an internal aneurysm [19]. Adopting this feature to hepatic AML, in the present case, tumor size well exceeded $4 \mathrm{~cm}$, meeting the criterion for the risk of rupture. However, no aneurysm was found by angiography at the time of transcatheter arterial embolization and pathological examination. Pregnancy is also one of the factors leading to rupture in a female patient [20].

\section{Conclusion}

We described a case of ruptured hepatic AML, which is, to the best of our knowledge, the sixth reported case. It was demonstrated histopathologically to be a variant of AML called epithelioid AML.

\section{Disclosure Statement}

The authors declare that they have no conflicts of interest. 


\begin{tabular}{l|l}
\hline Case Rep Oncol 2014;7:369-375 \\
\hline DOI: $10.1159 / 000363690$ & $\begin{array}{l}\text { @ 2014 S. Karger AG, Basel } \\
\text { www.karger.com/cro }\end{array}$ \\
\hline
\end{tabular}

Tajima et al.: Ruptured Hepatic Epithelioid Angiomyolipoma: A Case Report and Literature Review

\section{References}

1 Ishak KG: Mesenchymal tumors of the liver; in Okuda K, Peters RL (eds): Hepatocellular carcinoma. New York: John Wiley \& Sons, 1976, pp 247-307.

2 Goodman ZD, Ishak KG: Angiomyolipomas of the liver. The American Journal of Surgical Pathology 1984;8:745-750.

-3 Tsui WM, Colombari R, Portmann BC, et al: Hepatic angiomyolipoma: a clinicopathologic study of 30 cases and delineation of unusual morphologic variants. The American Journal of Surgical Pathology 1999;23:3448.

4 Ren N, Qin LX, Tang ZY, Wu ZQ, Fan J: Diagnosis and treatment of hepatic angiomyolipoma in 26 cases. World Journal of Gastroenterology: WJG 2003;9:1856-1858.

5 Li T, Wang L, Yu HH, et al: Hepatic angiomyolipoma: a retrospective study of 25 cases. Surgery Today 2008;38:529-535.

6 Zeng JP, Dong JH, Zhang WZ, Wang J, Pang XP: Hepatic angiomyolipoma: a clinical experience in diagnosis and treatment. Digestive Diseases and Sciences 2010;55:3235-3240.

7 Chang Z, Zhang JM, Ying JQ, Ge YP: Characteristics and treatment strategy of hepatic angiomyolipoma: a series of 94 patients collected from four institutions. Journal of Gastrointestinal and Liver Diseases: JGLD 2011;20:65-69.

8 Pea M, Bonetti F, Martignoni G, et al: Apparent renal cell carcinomas in tuberous sclerosis are heterogeneous: the identification of malignant epithelioid angiomyolipoma. The American Journal of Surgical Pathology 1998;22:180-187.

-9 Occhionorelli S, Dellachiesa L, Stano R, et al: Spontaneous rupture of a hepatic epithelioid angiomyolipoma: damage control surgery. A case report. Il Giornale di chirurgia 2013;34:320-322.

10 Wang Z, Gong Q, Fan Q: Expression of E-cadherin in angiomyolipoma. Human Pathology 2012;43:23482353.

-11 Konosu-Fukaya S, Nakamura Y, Fujishima F, et al: Renal epithelioid angiomyolipoma with malignant features: Histological evaluation and novel immunohistochemical findings. Pathology International 2014;64:133-141.

12 Nativ 0, Lindner A, Goldwasser B, Many M: Spontaneous rupture of renal angiomyolipoma. Report of three cases. European Urology 1984;10:345-346.

13 Chao CH, Lin CY, Chan SC, Chen KS: Concurrent hepatic and ruptured renal angiomyolipoma in tuberous sclerosis complex. Chang Gung Medical Journal 2004;27:696-700.

14 Aydin H, Magi-Galluzzi C, Lane BR, et al: Renal angiomyolipoma: clinicopathologic study of 194 cases with emphasis on the epithelioid histology and tuberous sclerosis association. The American Journal of Surgical Pathology 2009;33:289-297.

15 Brimo F, Robinson B, Guo C, Zhou M, Latour M, Epstein JI: Renal epithelioid angiomyolipoma with atypia: a series of 40 cases with emphasis on clinicopathologic prognostic indicators of malignancy. The American Journal of Surgical Pathology 2010;34:715-722.

16 Huber C, Treutner KH, Steinau G, Schumpelick V: Ruptured hepatic angiolipoma in tuberous sclerosis complex. Langenbecks Archiv fur Chirurgie 1996;381:7-9.

17 Guidi G, Catalano 0, Rotondo A: Spontaneous rupture of a hepatic angiomyolipoma: CT findings and literature review. European Radiology 1997;7:335-337.

18 Zhou YM, Li B, Xu F, et al: Clinical features of hepatic angiomyolipoma. Hepatobiliary and Pancreatic Diseases International: HBPD INT 2008;7:284-287.

19 Yamakado K, Tanaka N, Nakagawa T, Kobayashi S, Yanagawa M, Takeda K: Renal angiomyolipoma: relationships between tumor size, aneurysm formation, and rupture. Radiology 2002;225:78-82.

20 Pontis A, Piras B, Meloni A, De Lisa A, Melis GB, Angioni S: Rupture of renal angiomyolipoma in pregnancy. Journal of Obstetrics and Gynaecology: The Journal of the Institute of Obstetrics and Gynaecology 2013;33:628-629. 


\section{Case Reports in Oncology}

\begin{tabular}{l|l}
\hline Case Rep Oncol 2014;7:369-375 \\
\hline DOI: $10.1159 / 000363690$ & $\begin{array}{l}\text { C 2014 S. Karger AG, Basel } \\
\text { www.karger.com/cro }\end{array}$ \\
\hline
\end{tabular}

Tajima et al.: Ruptured Hepatic Epithelioid Angiomyolipoma: A Case Report and Literature Review

Table 1. Ruptured cases of hepatic AML in the English literature

\begin{tabular}{|c|c|c|c|c|c|c|c|}
\hline Case & First author & Year & Sex & Age & $\begin{array}{l}\text { Tumor } \\
\text { size, cm }\end{array}$ & Onset & Treatment \\
\hline 1 & Huber [16] & 1996 & $\mathrm{~F}$ & 22 & 8 & Hemorrhagic shock & Emergent resection \\
\hline 2 & Guidi [17] & 1997 & M & 74 & 10 & Upper abdominal pain & Emergent resection \\
\hline 3 & Tsui [3] & 1999 & M & 56 & 6.5 & n.a. & Emergent resection \\
\hline 4 & Zhou [18] & 2008 & n.a. & n.a. & 5 & Hemorrhagic shock & Emergent laparotomy for hemostasis \\
\hline 5 & Occhionorelli [9] & 2013 & $\mathrm{~F}$ & 25 & 9 & $\begin{array}{l}\text { Upper abdominal } \\
\text { pain }\end{array}$ & $\begin{array}{l}\text { Elective resection after emergent } \\
\text { laparotomy for hemostasis }\end{array}$ \\
\hline 6 & Present case & 2014 & M & 38 & 10.5 & $\begin{array}{l}\text { Upper abdominal } \\
\text { pain }\end{array}$ & $\begin{array}{l}\text { Elective resection after transcatheter } \\
\text { arterial embolization }\end{array}$ \\
\hline
\end{tabular}

n.a. $=$ Not available.
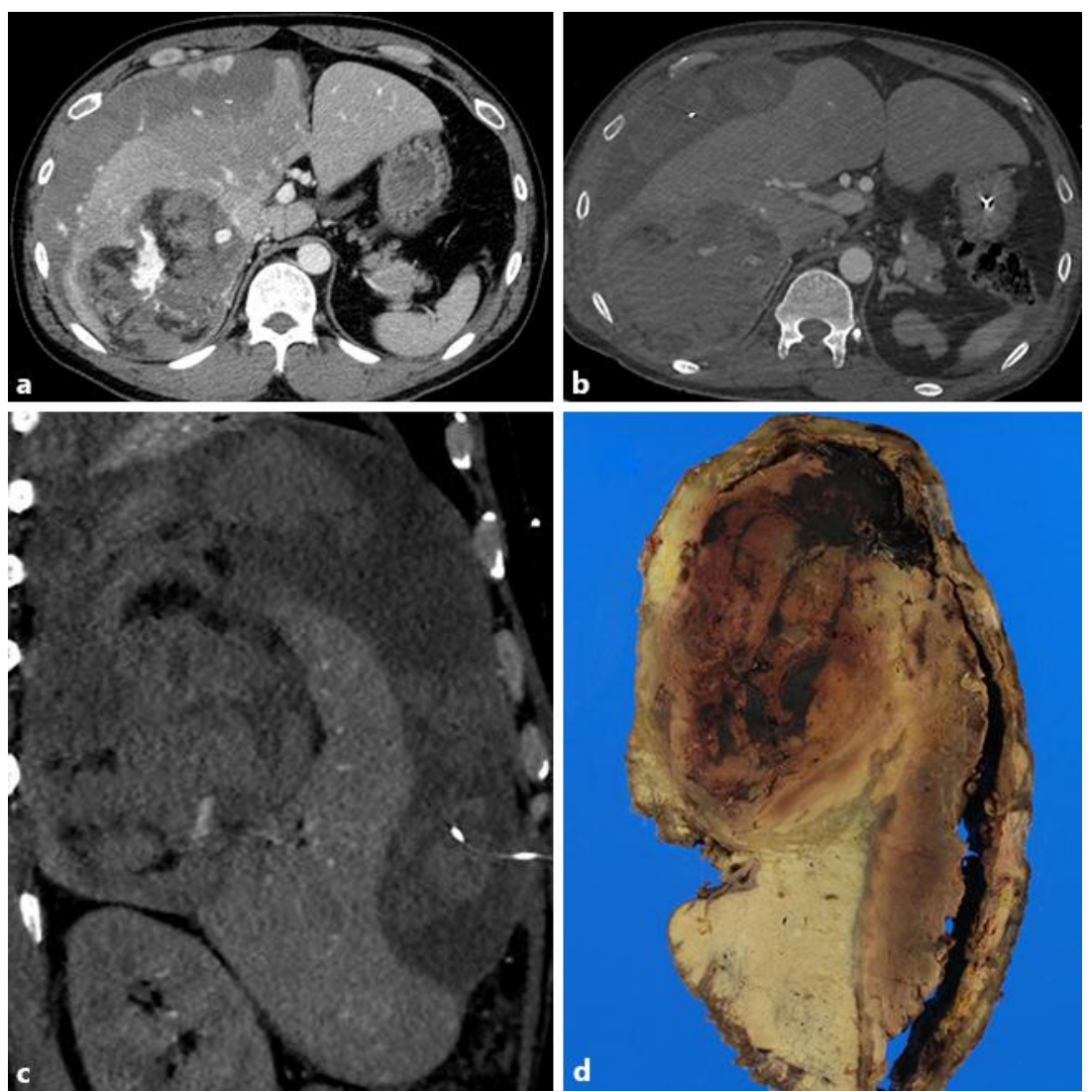

Fig. 1. a Contrast-enhanced CT revealed a hepatic AML with foci of low-density areas suggestive of fat. Extravasated contrast material was observed. b Preoperative contrast-enhanced CT demonstrated thickened capsule of hematoma. c Reconstructed sagittal section of $\mathbf{b}$ displayed a ruptured point in S7. d Cut surface of surgically resected specimen corresponding to the sagittal section of c showed hemorrhagic tumor and the ruptured point was confirmed. 
Tajima et al:: Ruptured Hepatic Epithelioid Angiomyolipoma: A Case Report and Literature Review

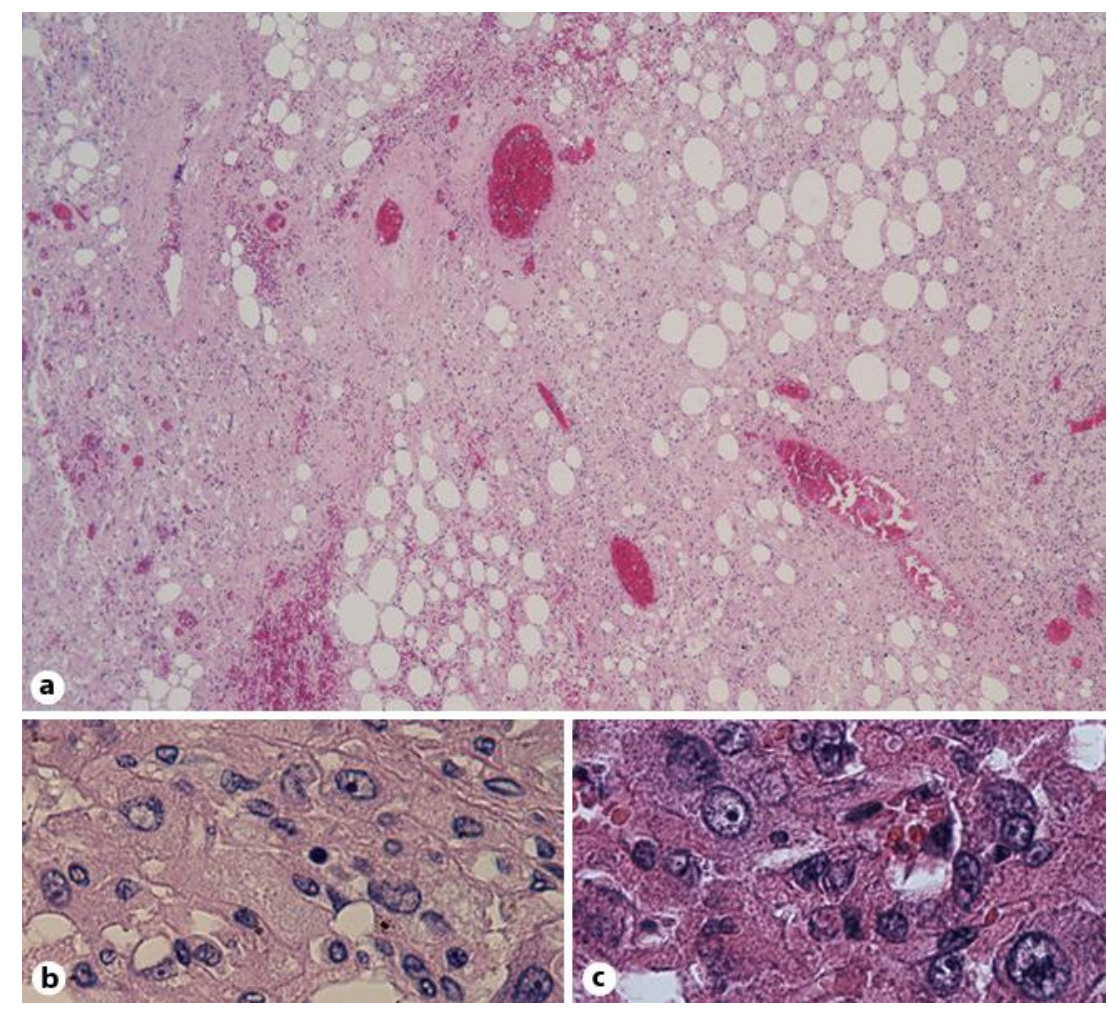

Fig. 2. a Microscopic findings demonstrated triphasic components, such as epithelioid cells, mature fat, and thickened-wall blood vessels $(\mathrm{HE}, \times 40)$. $\mathbf{b}$ Epithelioid cells were rounded or polygonal with abundant cytoplasm (HE, $\times 400)$. c Some of the epithelioid cells had enlarged or bizarre nuclei (HE, $\times 400)$. 
Tajima et al:: Ruptured Hepatic Epithelioid Angiomyolipoma: A Case Report and Literature Review

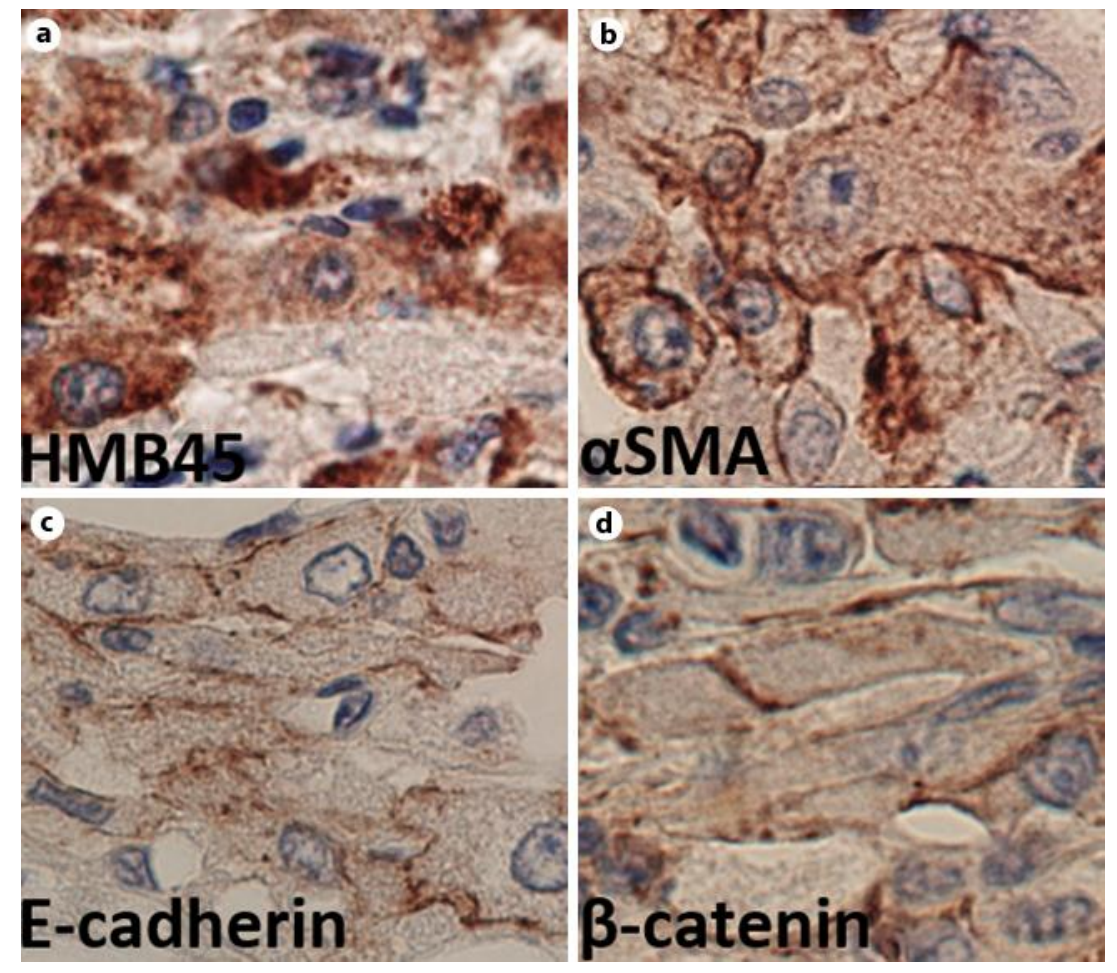

Fig. 3. a, b Cytoplasmic positivity for HMB45 and $\alpha$ SMA, respectively (immunostain, $\times 400$ ). c, d Weak membranous positivity for E-cadherin and $\beta$-catenin, respectively (immunostain, $\times 400$ ). 